\title{
Thermal management of machine compartment in a built-in refrigerator
}

\author{
Milind Devle ${ }^{l, *}$, Ankur Garg ${ }^{l}$, and Darci Cavali ${ }^{2}$ \\ ${ }^{1}$ Global Technology and Engineering Center, Whirlpool of India, Pune, 411014, India \\ ${ }^{2}$ Whirlpool Corporation, Michigan, 49022, USA
}

\begin{abstract}
In general a multi-door refrigerator machine compartment comprises of fan, condenser, compressor, control box, drain tray, and drain tubes. The performance of machine compartment depends upon the efficiency of heat extraction or heat exchange from heat generating components such as condenser and compressor. The efficiency of heat exchange can be improved by addressing two major factors, namely (1) Air bypass and (2) Hot air recirculation. The hot air recirculation in the machine compartment for builtin multi-door refrigerator configuration is the focus of this study. The results from Computational Fluid Dynamics (CFD) simulations show that efficiency of heat exchange for built-in application is lower than that for free-standing configuration. Recirculation of hot air and reduction in airflow are the two major factors which contribute towards the variation in machine compartment performance. The CFD simulations were coupled with Partial Factorial Design of Experiment (DoE) approach to systematically investigate the effect of variables such as (a) side gap and top gap between kitchen cabinetry and the refrigerator, (b) the baffle/flap (i.e. back and bottom of machine compartment) on the performance effectiveness of machine compartment. The results of the simulation provided critical design improvement directions resulting in performance improvement. Furthermore, the CFD simulation results were also compared to test data and the results compared favourably.
\end{abstract}

\section{Introduction}

Refrigerator machine compartment comprises of compressor, condenser, fan and many other module sets [1-2]. The components and their arrangement must be designed to improve the cooling, structural and noise performances of the refrigerator. A typical multi-door refrigerator machine compartment is as shown in Fig. 1. The overall performance of a refrigerator depends on the compressor and condenser heat dissipation or exchange from the system during operation [3]. In addition, the performance of machine compartment depends on the refrigerator installation configuration (i.e. free-standing or built-in configuration). In general, the depth of a freestanding multi-door refrigerator is approximately double that of built-in multi-door refrigerator. When a freestanding multi-door refrigerator is installed as a built-in configuration, the multi-door refrigerator typically does not perform well, resulting in compressor tripping due to heat-up of compressor. To provide installation flexibility and a greater customer choice, it is important that the machine compartment in a multi-door refrigerator be designed such that the thermal loading of the machine compartment remains within acceptable limits for both free-standing and built-in configurations.

Computational Fluid Dynamics is a well known tool for understanding the flow and thermal behaviour [4-5]. In this study, Computational Fluid Dynamics (CFD) simulation has been used to investigate the built-in refrigerator thermal dynamics. Visualization of temperature rise inside the machine compartment is critical to understand the thermal loading that exists inside the refrigerator machine compartment.

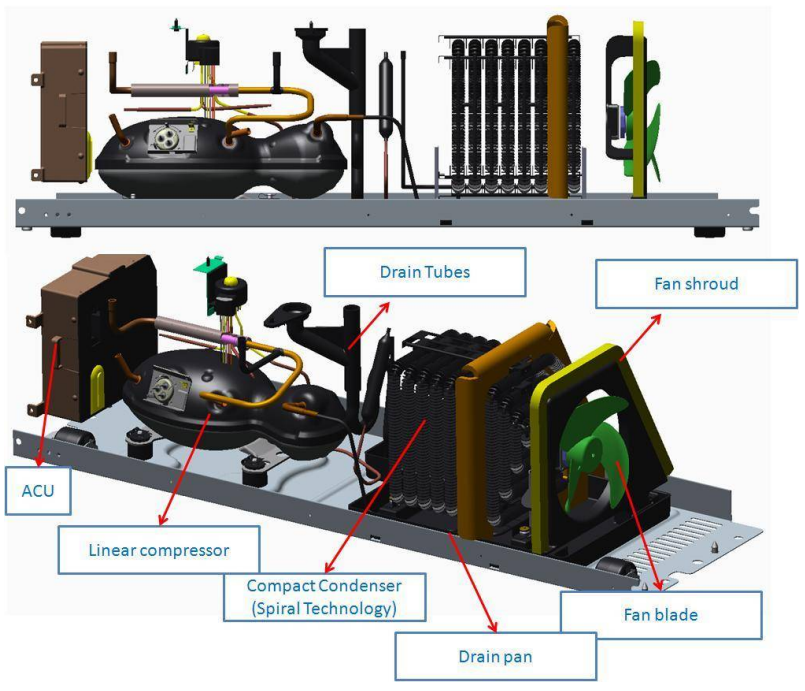

Fig. 1. Machine compartment architecture with spiral condenser and linear compressor.

The current study was conducted in two phases. For phase-1, CFD simulation was used to investigate the

\footnotetext{
* Corresponding author: milind devle $@$,whirlpool.com
} 
performance of multi-door refrigerator for the two installation configuration. The results from these simulations were analyzed to identify the root cause behind the thermal overloading of the machine compartment, particular the compressor. For phase-2, CFD simulations were coupled with a Partial factorial Design of Experiments (DoE) to assess the impact of various parameters on the thermal performance of the machine compartment.

\section{Modelling methodology}

\subsection{Description of multidoor refrigerator}

Generally, free-standing and built-in refrigerators are multi-door, in which evaporators are placed in compartments which are covered so as to have a unique aesthetic look. Fan allows the warm air to flow over the evaporator from compartments to lower the temperature and dehumidify it. The remaining components of cooling systems such as condenser and compressor are placed at back and bottom side of the refrigerator compartment called as machine compartment. The machine compartment also consists of the fan for forced cooling. In built-in, the multi-door refrigerator is positioned inside kitchen cabinetry. The warm air passage in builtin refrigerators is important to model as it affects the performance and energy efficiency.

\subsection{Assumptions}

The following assumptions are made in this study:

- Convective temperature profiles are considered for the freezer and refrigerator compartments,

- Constant temperature profiles are considered for condenser and compressor,

- Steady state condition is assumed for simulation,

- Boussinesq assumption is used to model the buoyancy effects,

- The flow is assumed to be turbulent and Spalart Allmaras turbulence model is used,

- Fluid flow is assumed to be incompressible.

\subsection{Fluid or CFD model}

Fluid modeling was carried out in Creo 3.0 using the master assembly of multi-door refrigerator. The freezer and refrigerator compartment fluids are modelled as void, but the refrigerator structure that are body and door are modelled as solid structure. The compressor and condenser are modelled as void and the fan is modelled as rotating fluid domain considering Moving Reference Frame (MRF) methodology. The base plate and back plate are modelled as solid domains whereas the machine compartment air is modelled as fluid domain. Surrounding air is assumed as ambient fluid domain. For built-in configuration, the kitchen cabinetry is also modelled. Fig 2 shows the CFD model for free-standing and built-in configurations.
The fluid model is meshed using Fluid-Nexus version 1.5.4 software. The material properties used in this study are summarized in Table 1. The boundary conditions used in this study are tabulated in Table 2. The commercial CFD solver, Acusolve version 13 is used for the CFD simulations and the solver settings used in this study are summarized in Table 3 .

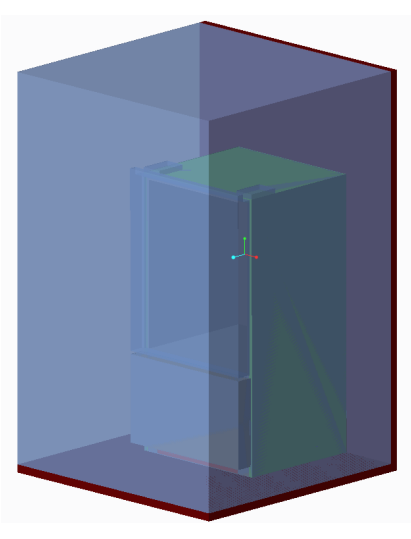

Free-standing

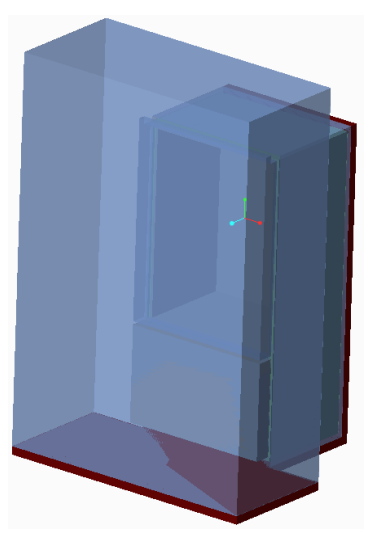

Built-in
Fig. 2A. Typical CFD model for free-standing and built-in.

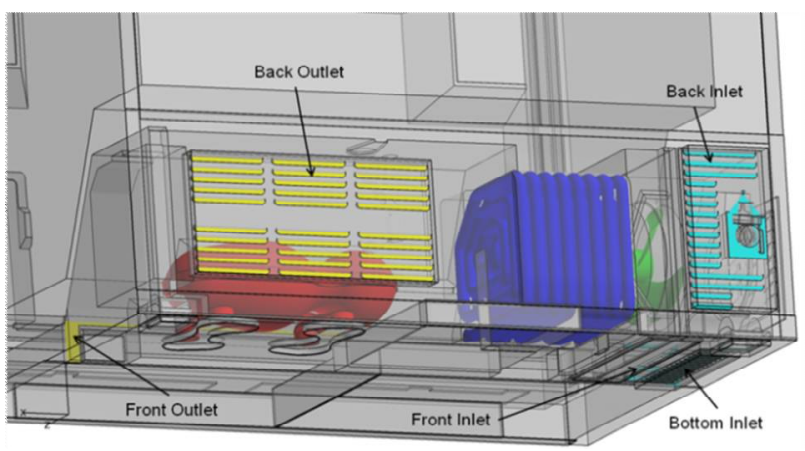

Fig. 2B. Locations where the simulation data extracted.

Fig. 2. Fluid/ CFD model.

Table 1. Material properties.

\begin{tabular}{|l|c|c|c|}
\hline & Plastic & Al & Foam \\
\hline Density, $\rho(\mathrm{kg} / \mathrm{m} 3)$ & 1021.5 & 2658 & 32 \\
\hline Sp. Heat, $\mathrm{Cp}(\mathrm{J} / \mathrm{kg}-\mathrm{K}))$ & 960 & 998 & 500 \\
\hline Conductivity, $\mathrm{k}(\mathrm{W} /(\mathrm{m}-\mathrm{K}))$ & 0.16 & 235 & 0.018 \\
\hline & \multicolumn{4}{|l|}{ Gasket } & Steel & Air \\
\hline Density, $\rho(\mathrm{kg} / \mathrm{m} 3)$ & 20 & 7850 & 1.185 \\
\hline Sp. Heat, $\mathrm{Cp}(\mathrm{J} / \mathrm{kg}-\mathrm{K}))$ & 960 & 449 & 1005 \\
\hline Conductivity, k (W/(m-K)) & 0.06 & 72.8 & 0.0233 \\
\hline Viscosity, $\mu\left(\mathrm{kg}-\mathrm{m} / \mathrm{s}^{2}\right)$ & -- & -- & $1.6 \mathrm{E}-05$ \\
\hline
\end{tabular}


Table 2. Boundary condition details considered for simulation.

\begin{tabular}{|l|l|}
\hline Location & Boundary condition type \\
\hline $\begin{array}{l}\text { Freezer } \\
\text { compartment }\end{array}$ & Convective wall \\
\hline $\begin{array}{l}\text { Refrigerator } \\
\text { Compartment }\end{array}$ & Convective wall \\
\hline Ambient domain & Convective wall \\
\hline Condenser coils & Weighted average const. temp \\
\hline
\end{tabular}

Table 3. Acusolve Solver Settings.

\begin{tabular}{|l|l|l|}
\hline & Mode & steady-state \\
\hline \multirow{5}{*}{ Equation } & Flow & Navier Stoke \\
\cline { 2 - 3 } & Temperature & $\begin{array}{l}\text { Advection } \\
\text { Diffusion }\end{array}$ \\
\cline { 2 - 3 } & Radiation & Enclosure \\
\cline { 2 - 3 } & Species & None \\
\cline { 2 - 3 } & Turbulence & $\begin{array}{l}\text { Spalart } \\
\text { Allmaras }\end{array}$ \\
\cline { 2 - 3 } Solution & $\begin{array}{l}\text { Mesh } \\
\text { sum_krylov_vector }\end{array}$ & 70 \\
\cline { 2 - 3 } & Eulerian \\
\hline \multirow{4}{*}{} & Relaxation & 0.3 \\
\hline
\end{tabular}

\section{Result and discussion}

\subsection{Phase 1}

To identify the performance variation of same multidoor refrigerator between two different installing conditions through Computational Fluid Dynamics (CFD) simulation, parameters like the flow rate, the heat exchange from condenser-compressor and the air temperature before fan inlet data are extracted. The data are summarized in Tables 4 and 5. For a better insight, the temperature contour on a plane passing through the machine compartment and temperature streamline are captured as shown in Fig 3 and 4.

Through the CFD simulation of Phase1, it is observed that, the total flow rate for built-in configuration is reduced by $8 \%$ as compared to free-standing, as the flow passage around the refrigerator in built-in got reduced. The total heat exchange for built-in configuration is reduced by $45 \%$ as compared to free-standing configuration, which can be attributed to high inlet temperature (as hot air recirculation observed) and less flow rate. The compressor heat exchange seems to be similar in both situations as compared to condenser since compressor is always surrounded by hot air.

\subsection{Phase 2}

Based on the Phase1 results, hot air recirculation was identified as the major contributor for the refrigerator performance reduction. To increase the performance of built-in refrigerator, the partial factorial Design of Experiment (DOE) is considered with following performance affecting variables with the ranges as shown in Table 6.

Table 4. Normalized flow rate details.

\begin{tabular}{|l|l|l|l|l|l|l|}
\hline \multicolumn{7}{|c|}{ Normalized Flow Rate [cfm] } \\
\hline & Total & $\begin{array}{l}\text { Back } \\
\text { Inlet }\end{array}$ & $\begin{array}{l}\text { Bottom } \\
\text { Inlet }\end{array}$ & $\begin{array}{l}\text { Front } \\
\text { Inlet }\end{array}$ & $\begin{array}{l}\text { Back } \\
\text { Outlet }\end{array}$ & $\begin{array}{l}\text { Front } \\
\text { Outlet }\end{array}$ \\
\hline $\begin{array}{l}\text { Free } \\
\text { Standing }\end{array}$ & 100.0 & 55.77 & 31.03 & 14.2 & 79.02 & 20.98 \\
\hline Built-in & 91.84 & 48.58 & 25.43 & 18.3 & 70.35 & 21.49 \\
\hline
\end{tabular}

Table 5. Normalized heat exchange and average temperature of plane before fan inlet.

\begin{tabular}{|c|c|c|c|c|}
\hline \multicolumn{3}{|c|}{ Normalized Heat Exchange [W] } & $\begin{array}{c}\text { Normalized } \\
\text { Avg. Temp @ } \\
\text { fan front plane } \\
{\left[{ }^{\circ} \mathrm{F}\right]}\end{array}$ \\
\hline $\begin{array}{c}\text { Free } \\
\text { Standing }\end{array}$ & 72.04 & 27.96 & 100.00 & 100.00 \\
\hline Built-in & 33.16 & 22.16 & 55.34 & 107.94 \\
\hline
\end{tabular}

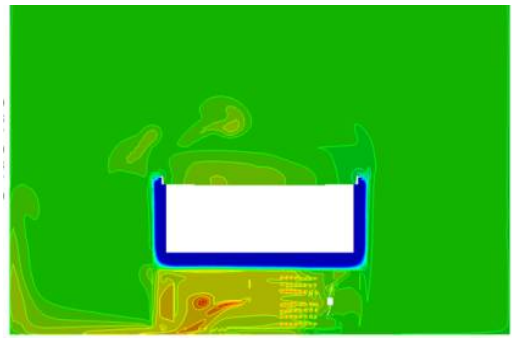

Free standing

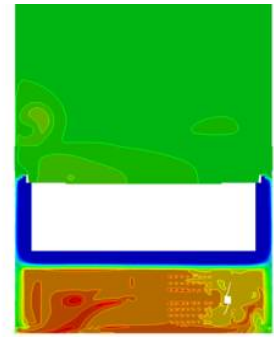

Built-in
Fig. 3. Temperature contour on plane passing through the machine compartment.

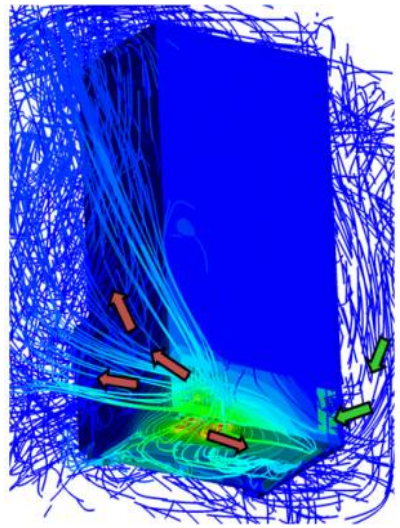

Free standing

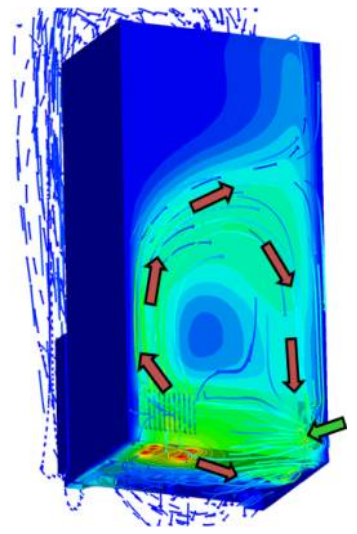

Built-in
Fig. 4. Temperature contour with streamline. 
Table 6. DoE variables.

\begin{tabular}{|l|l|l|l|}
\hline X's & Factors & - & + \\
\hline X1 & Back flap & - & + \\
\hline X2 & Side restriction & - & + \\
\hline X3 & Top restriction & - & + \\
\hline X4 & Bottom flap & - & + \\
\hline & \multicolumn{3}{|l}{} \\
\hline Y's & Factors & \\
\hline Y1 & Airflow over condenser fan (cfm) \\
\hline Y2 & Overall heat exchange (W) \\
\hline Y3 & Average temperature at compressor ( $\left.{ }^{\circ} \mathrm{F}\right)$ \\
\hline
\end{tabular}

As per the partial factorial DOE, eight cases were considered for simulation. Case details are summarized as in Table 7. Flowrate, heat exchange from compressorcondenser and the temperature at fan inlet results are tabulated in Tables 8 and 9.

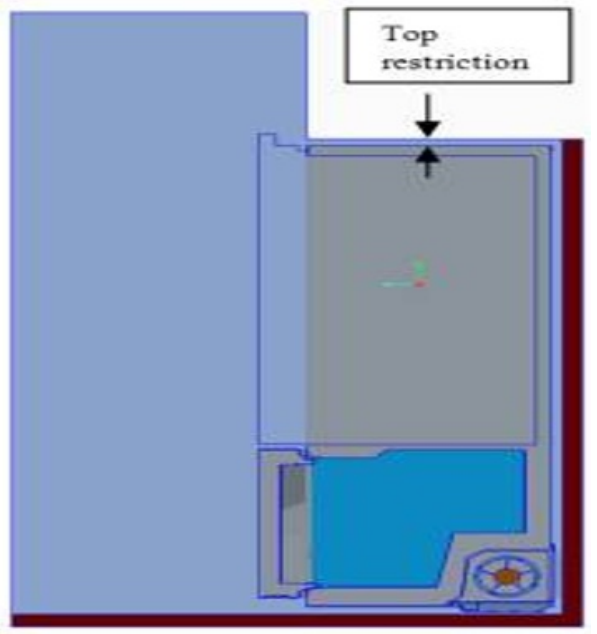

Fig. 5A. Representing top restriction.

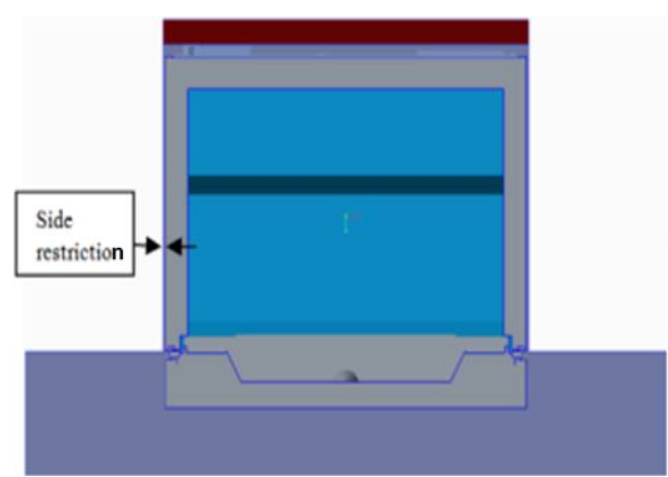

Fig. 5B. Representing side restriction.

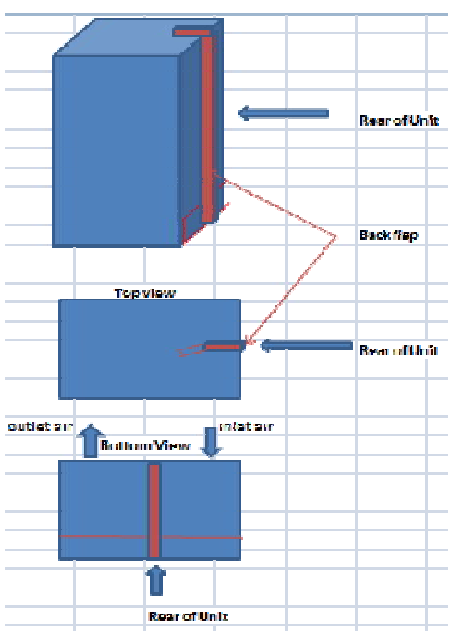

Fig. 5C. Representing back and bottom flaps.

Fig. 5. DOE variable schematic representation.

Table 7. DoE case details.

\begin{tabular}{|c|c|c|c|c|}
\hline & $\begin{array}{c}\text { Back } \\
\text { flap }\end{array}$ & $\begin{array}{c}\text { Side } \\
\text { restrictions }\end{array}$ & $\begin{array}{c}\text { Top } \\
\text { restrictions }\end{array}$ & Bottom flap \\
\hline Run 1 & - & + & + & - \\
\hline Run 2 & - & + & - & + \\
\hline Run 3 & - & - & + & + \\
\hline Run 4 & - & - & - & - \\
\hline Run 5 & + & + & + & + \\
\hline Run 6 & + & + & - & - \\
\hline Run 7 & + & - & + & - \\
\hline Run 8 & + & - & - & + \\
\hline
\end{tabular}

Table 8. Partial DOE flowrate details in cfm (change over the Phase 1 built-in configuration).

\begin{tabular}{|l|c|c|c|c|c|c|}
\hline & Total & $\begin{array}{c}\text { back } \\
\text { inlet }\end{array}$ & $\begin{array}{c}\text { bottom } \\
\text { inlet }\end{array}$ & $\begin{array}{c}\text { front } \\
\text { inlet }\end{array}$ & $\begin{array}{c}\text { back } \\
\text { outlet }\end{array}$ & $\begin{array}{c}\text { front } \\
\text { outlet }\end{array}$ \\
\hline Run 1 & 1.04 & 1.52 & -0.87 & 0.24 & 1.88 & -1.21 \\
\hline Run 2 & 0.79 & 2.51 & -1.02 & -0.85 & 2.12 & -1.78 \\
\hline Run 3 & 0.01 & 2.57 & -1.33 & -1.38 & 1.67 & -1.87 \\
\hline Run 4 & 0.43 & 1.07 & -0.91 & 0.12 & 1.58 & -1.29 \\
\hline Run 5 & -5.18 & -2.12 & -1.68 & -1.54 & -3.68 & -1.82 \\
\hline Run 6 & -1.91 & -2.23 & -0.15 & 0.31 & -1.67 & -0.77 \\
\hline Run 7 & -2.24 & -1.80 & -0.89 & 0.30 & -1.57 & -1.00 \\
\hline Run 8 & -5.13 & -1.55 & -2.43 & -1.30 & -4.01 & -1.69 \\
\hline
\end{tabular}


Table 9. Partial DOE heat exchange and average temperature of plane before fan inlet (change over the Phase 1 built-in).

\begin{tabular}{|c|c|c|c|c|}
\hline & \multicolumn{3}{|c|}{ Heat Exchanged [W] } & $\begin{array}{c}\text { Avg. Temp @ } \\
\text { fan front } \\
\text { plane [ }{ }^{\circ} \text { F] }\end{array}$ \\
\hline Total & Condenser & Compressor & -0.10 \\
\hline Run 1 & -1.38 & -0.06 & -1.31 & -2.07 \\
\hline Run 3 & 4.84 & 5.34 & -0.49 & -1.99 \\
\hline Run 4 & 1.28 & 1.90 & -0.61 & -0.65 \\
\hline Run 5 & 20.39 & 20.02 & 0.37 & -8.67 \\
\hline Run 6 & 10.45 & 10.61 & -0.15 & -4.45 \\
\hline Run 7 & 10.22 & 10.14 & 0.08 & -4.07 \\
\hline Run 8 & 19.11 & 19.01 & 0.11 & -8.38 \\
\hline
\end{tabular}

\subsection{Parametric study}

CFD data from Tables 8 and 9 are evaluated using the statistical JMP software to find the effectiveness of each variable against the Y's mentioned in Table 6. It is observed that, the total airflow varies with delta variation of $6.22 \mathrm{cfm}$, total heat exchange varies with delta variation of $20.47 \mathrm{~W}$ and average temperature at fan front plane varies with delta variation of $8.57^{\circ} \mathrm{F}$. Also, the fit model analysis for each variable against Y's are also plotted.

\subsubsection{Effect on total airflow}

The total airflow fit model analysis is shown in Fig 6 . The major variation in the total airflow is coming from back flap and the bottom flap. Total airflow of machine compartment got reduced by $11 \%$ and $7 \%$ because of back flap and bottom flap. Top and side restrictions are having negligible effect on total airflow.

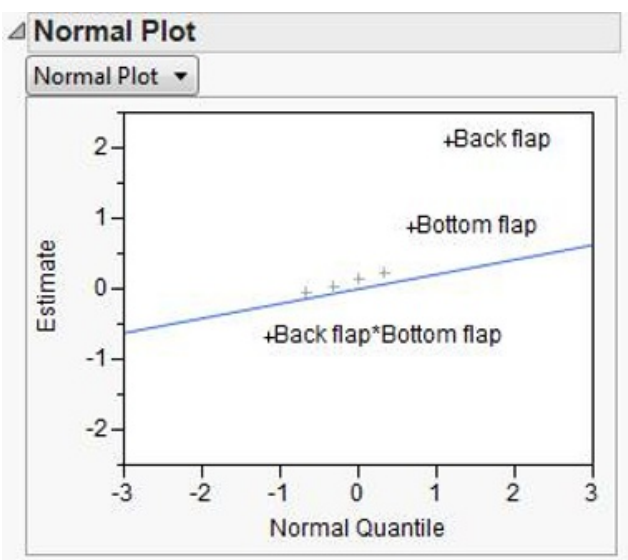

Fig. 6A. JMP normal plot for total airflow.

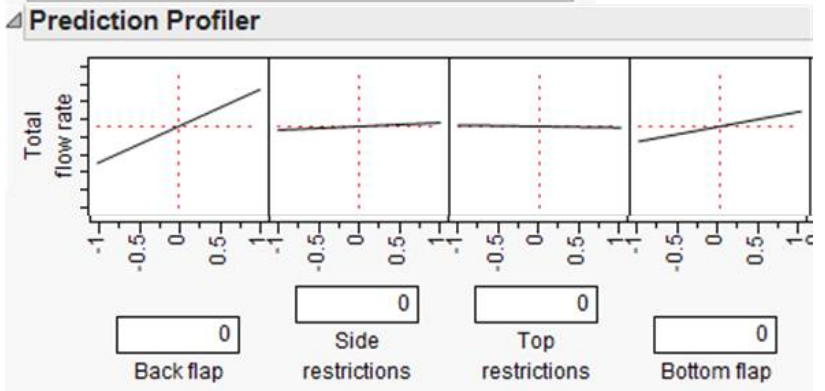

Fig. 6B. Fit model analysis for total airflow.

Fig. 6. Fit model analysis for total airflow.

\subsubsection{Effect on total heat exchange}

The total heat exchange fit model analysis is shown in Fig 7. The major variation in the total heat exchange is coming from back flap and the bottom flap. The total heat exchange in machine compartment is increased by $35 \%$ and $20 \%$ because of the back and bottom flap respectively. Top and side restrictions are having negligible effect on total heat exchange.

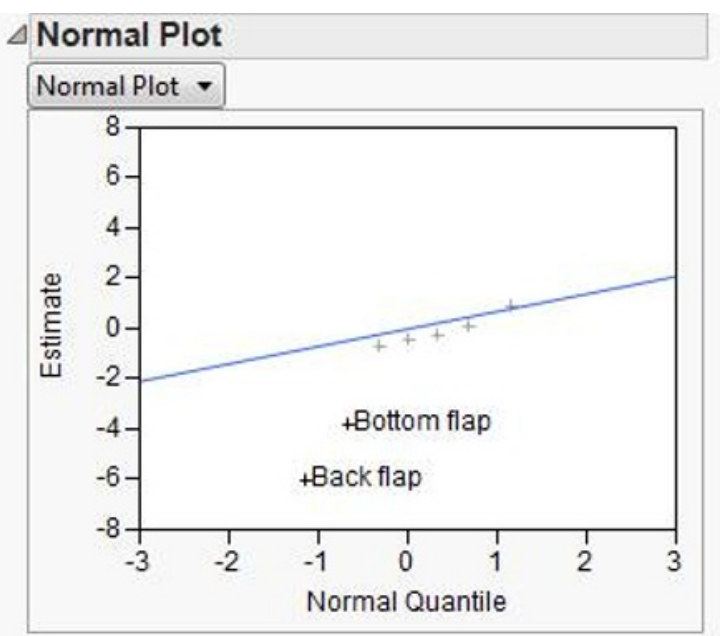

Fig. 7A. JMP normal plot for total heat exchange.

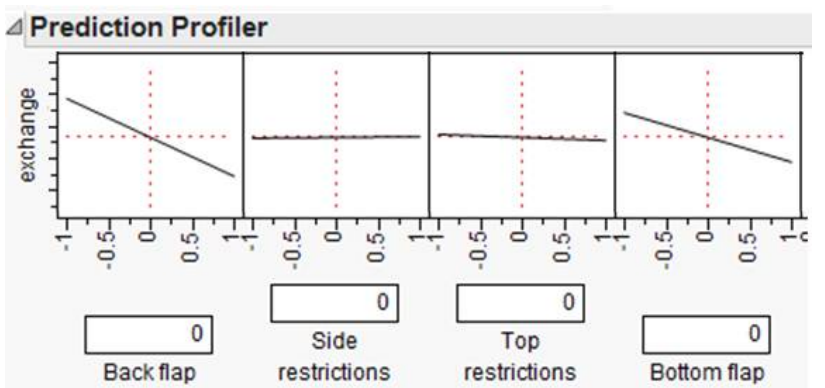

Fig. 7B. Prediction profile of each variable for total heat exchange.

Fig. 7. Fit model analysis for Total heat exchanged.

\subsubsection{Effect on average temperature at fan front plane}

The average plane temperature fit model analysis as shown in Fig 8. The major variation in the average 
temperature at fan front plane is coming from back flap and the bottom flap. The average temperature at fan front plane is reduced by $5 \%$ and $3 \%$ because of the back and bottom flap respectively. Top and side restrictions are having negligible effect on average temperature at fan front plane.

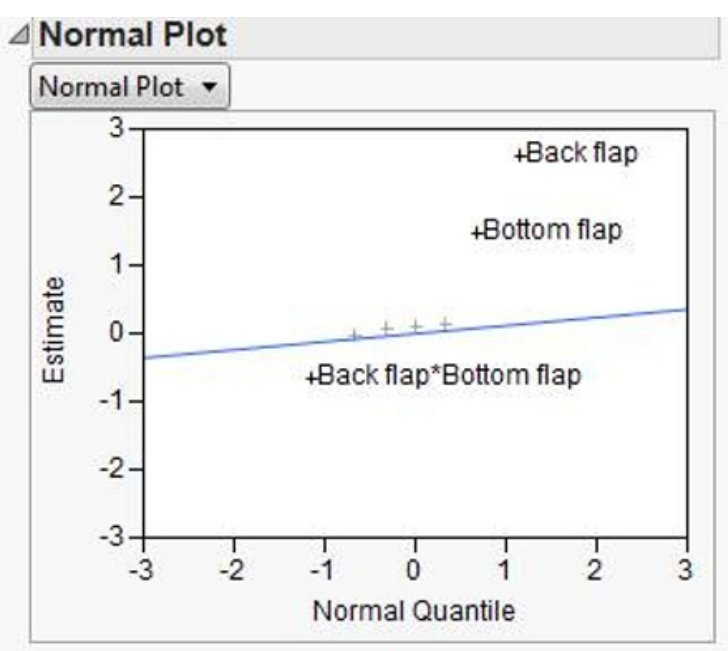

Fig. 8A. JMP normal plot for total average temperature at plane before fan inlet.

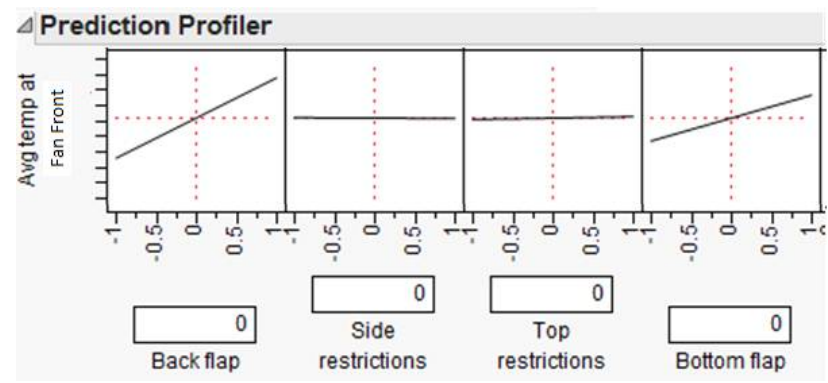

Fig. 8B. Prediction profile of each variable average temperature at plane before fan inlet.

Fig. 8. Fit model analysis for average temperature of plane before fan inlet.

\subsection{D energy simulation}

1D energy simulation with and without flaps were performed. The data of 1D simulation is summarized in Fig 9. Through 1D simulation data it is observed that the refrigerator in built in application with current condition (i.e without flaps) is not recommended, as it generates $75 \%$ of hot air recirculation at inlet of machine compartment. Due to this, the compressor temperature increases over the operating limit. The proposed changes reduces the hot air recirculation from the original $75 \%$ down to $26 \%$, which provides $20 \%$ energy benefit and allows the system to operate back within the allowable range of the compressor.

\subsection{Field test}

1D From overall simulation study it was observed that, the built-in refrigerator with flaps can prove to be an efficient option for improved performance. Thus, testing was performed on built-in multi-door refrigerator with bottom and back flaps using field condition where operating conditions are cyclic in nature. The test data is summarized in Table 10. From the testing, refrigerator with flaps shows following improvements:

- Average freeze compartment (FC) temperature colder by $0.4^{\circ} \mathrm{F}$

- Average refrigerator compartment (RC) temperature colder by $2{ }^{\circ} \mathrm{F}$

- Condenser in temperature: colder by $14^{\circ} \mathrm{F}$

- Condenser out temperature: colder by $7^{\circ} \mathrm{F}$

- Compressor temperature is less than the operating limit so tripping would be avoided

- Compressor run time: $2.5 \%$ less

- Energy consumption: 4\% improvement

\begin{tabular}{|ccc|} 
Product characteristic & Unit & Difference \\
\hline RC temp & {$[\mathrm{F}]$} & -0.4 \\
\hline PN temp & {$[\mathrm{F}]$} & -0.2 \\
\hline FC temp & {$[\mathrm{F}]$} & -0.3 \\
\hline IB temp & {$[\mathrm{F}]$} & -0.3 \\
\hline FC evap temp & {$[\mathrm{F}]$} & -1.2 \\
\hline RC evap temp & {$[\mathrm{F}]$} & -3.7 \\
\hline FC cond temp & {$[\mathrm{F}]$} & -21.3 \\
\hline RC cond temp & {$[\mathrm{F}]$} & -33.0 \\
\hline Deck air flow & {$[\mathrm{CFM}]$} & -6.1 \\
\hline FC power & {$[\mathrm{W}]$} & -4.9 \\
\hline RC power & {$[\mathrm{W}]$} & -17.7 \\
\hline FC run time & {$[\%]$} & $-5.7 \%$ \\
\hline RC run time & {$[\%]$} & $-6.0 \%$ \\
\hline Total run time & {$[\%]$} & $-11.7 \%$ \\
\hline Test energy & {$[\mathrm{kWh} /$ day] } & $-22.4 \%$ \\
\hline Total energy consumption & {$[\mathrm{kWh} /$ day] } & $-19.8 \%$ \\
\hline
\end{tabular}

Fig. 9. 1D energy simulation data: Difference between without and with flaps.

Table 10. Normalized test data with and without flaps.

\begin{tabular}{|l|l|l|l|l|}
\hline Case & $\begin{array}{l}\text { Avg. FC } \\
\text { Temp } \\
{\left[{ }^{\circ} \mathrm{F}\right]}\end{array}$ & $\begin{array}{l}\text { Avg. RC } \\
\text { Temp } \\
{\left[{ }^{\circ} \mathrm{F}\right]}\end{array}$ & $\begin{array}{l}\text { Condenser } \\
\text { In Temp } \\
{\left[{ }^{\circ} \mathrm{F}\right]}\end{array}$ & $\begin{array}{l}\text { Condenser } \\
\text { Out Temp } \\
{\left[{ }^{\circ} \mathrm{F}\right]}\end{array}$ \\
\hline $\begin{array}{l}\text { Refriger } \\
\text { ator } \\
\text { with } \\
\text { flaps }\end{array}$ & 0 & 31.8 & 150.84 & 102.56 \\
\hline $\begin{array}{l}\text { Refriger } \\
\text { ator } \\
\text { without } \\
\text { flaps }\end{array}$ & 0.4 & 33.7 & 164.84 & 109.4 \\
\hline $\begin{array}{l}\text { Case } \\
{[\mathrm{kWh} / \text { day }]}\end{array}$ & $\begin{array}{l}\text { Energy Consumption } \\
{[\%]}\end{array}$ & $\begin{array}{l}\text { Compressor On Time } \\
{[\%]}\end{array}$ \\
\hline $\begin{array}{l}\text { Refriger } \\
\text { ator } \\
\text { with } \\
\text { flaps }\end{array}$ & 0.96 & 0.98 \\
\hline $\begin{array}{l}\text { Refriger } \\
\text { ator } \\
\text { without } \\
\text { flaps }\end{array}$ & 1.00 & 1.00 \\
\hline
\end{tabular}




\section{Conclusions}

The study compares the performance of the multi-door machine compartment in free-standing and built-in configurations. The study includes the parametric study which proved to be an effective tool to show the effect of various parameters on performance of machine compartment in built-in situation.

The results from the CFD show that the performance of machine compartment in built-in configuration is negatively impacted and there is need to study this aspect. From the overall DOE analysis it is observed that, the back flap and the bottom flap have a major impact on the amount of heat exchange and on the temperature at the fan front. Due to flaps, the efficiency of built-in refrigerator machine compartment is increased by around $35 \%$ thereby increasing almost $50 \%$ of fresh air intake at fan inlet. Also, the condenser out temperature is reduced by around $20 \%$. Thus, the proposed flaps in built-in refrigerator provide to be efficient since the operating condition seems to be in controlled working condition of compressor and temperature overshoot could be avoided to a large extent.

\section{References}

1. N. Z. Adkane, S. V. Borkar, and R. D. Bokde, IRJET, 4, 6 (2017)

2. P. Tiwari, P. Pandey, and Dr. S. P. S. Rajput, IRJET, 4, 5 (2017)

3. J. R. Barbosa, Jr. Christian, J. L. Hermes, and C. Melo, J. Braz. Soc. Mech. Sci. \& Eng, 32, 445-453 (2010).

4. S Logeshwaran, JCHPS, 9, 4 (2016).

5. M. E. Haque, R. A. Bakar, G. L. Ming, and M. Shakaib, JEAS, 12, 3054-3060 (2017). 